\title{
Developing the Alliances to Expand Traditional Indigenous Healing Practices Within Alberta Health Services
}

\author{
Jazmine Leigh Drost, $\mathrm{MPH}, \mathrm{MA}^{1,2}$
}

\begin{abstract}
Objectives: Indigenous people have unique health needs that require culturally appropriate holistic care that addresses physical, mental, emotional, and spiritual health. Access to both traditional Indigenous healing practices and Western medicine are needed for all encompassing holistic health.

Design: This inquiry addresses actions suggested by the United Nations (UN) and the Truth and Reconciliation Commission of Canada (TRC) with regard to traditional Indigenous medicine and healing and was guided by an Organizational Sponsor and Inquiry Team.

Setting: The fieldwork for this study took place within Alberta Health Services (AHS), established in 2008 when 12 separate health entities merged to become Canada's first and largest fully integrated provincial health system.

Participants: Two Elders and a Cultural Helper provided perspectives on cultural protocols surrounding the traditional Indigenous sweat lodge ceremony. Three Indigenous community members provided perspectives on AHS services and holistic health through participation in the traditional Indigenous sweat lodge ceremony. Seven AHS administrative employees provided perspectives on implementation.

Interventions: This study was conducted within an action research framework and the researcher conducted a literature review, interviews, and a focus group to allow for triangulation.

Results: Throughout the interviews and focus group, participants consistently emphasized the importance of increasing efforts to expand traditional Indigenous healing practices within AHS, giving rise to the primary study theme: Expanding Traditional Indigenous Healing Practices within AHS. Several subthemes emerged in support of this primary focus, including the following: (1) enhancing cultural competency and safety training among leadership and employees; (2) adhering to tradition and protocol; (3) establishing meaningful partnerships; (4) strengthening organizational facets of program delivery; and (5) need for additional financial, human, and logistical resources.

Conclusions: During this time of reconciliation with Indigenous peoples in Canada and beyond, health care leaders and providers have an ethical responsibility and important opportunity to help improve the troubling health disparities at hand. This will inevitably require tremendous reflection, humility, courage, and commitment by stakeholders at all levels, as they work to transform health systems that disproportionately disadvantage Indigenous ways of knowing and being while implicitly privileging Eurocentric, biomedical perspectives. This pursuit, despite the barriers that may arise, is a moral, social, and political imperative for all those health care workers who seek to reduce suffering.
\end{abstract}

Keywords: Indigenous health, holistic health, integrative health services, traditional healing practices, sweat lodge

\footnotetext{
${ }^{1}$ Royal Roads University, Victoria, Canada.

${ }^{2}$ Population, Public and Indigenous Health, Alberta Health Services, Calgary, Canada.
} 


\section{Introduction}

$\mathbf{T}$ HERE ARE TROUBLING GAPS IN health outcomes between Indigenous* people living in the Canadian province of Alberta, and non-Indigenous Albertans. In 2015, the life expectancy of Indigenous people living in Alberta and nonIndigenous Albertans at birth was reported to be 70.4 and 82.3 years, respectively, representing a gap of 11.9 years. ${ }^{1}$ Indigenous people have unique health needs that require culturally appropriate holistic care that addresses physical, mental, emotional, and spiritual health. ${ }^{2}$ Therefore, relying solely on biomedical principles when addressing Indigenous health is not necessarily effective, as it ignores the essential dimension of spirituality in Indigenous healing. ${ }^{3,4}$ Access to both traditional Indigenous healing practices and Western medicine are thus needed for all encompassing holistic health.

This inquiry is centered around a particular Canadian health care setting and aligns with actions suggested by the United Nations (UN) and the Truth and Reconciliation Commission of Canada (TRC) with regard to traditional Indigenous medicine and healing. More specifically, this work investigates the implementation of culturally appropriate protocols surrounding traditional Indigenous healing practices offered within the parameters of provincially funded health care.

The fieldwork for this study took place within Alberta Health Services (AHS), established in 2008 when 12 separate health entities merged to become Canada's first and largest fully integrated provincial health system. ${ }^{5}$ AHS governs and operates Alberta Hospital Edmonton (AHE), a hospital providing mental health services to adults. ${ }^{6} \mathrm{AHE}$ is home to a traditional Indigenous sweat lodge (explained below). Elder $^{\dagger}$ Emil Durocher ${ }^{\dagger}$ is the sweat lodge keeper of the AHE traditional Indigenous sweat lodge and holds traditional Indigenous sweat lodge ceremonies for AHS clients and employees, along with community members.

Indigenous peoples have been holding and participating in sacred Indigenous sweat lodge ceremonies for centuries. As Schiff and Pelech explain, "the term sweat lodge is used to denote both a place and a ceremony" while acknowledging there are variations among and within different Indigenous groups. ${ }^{7}$ The traditional Indigenous sweat lodge takes place in a circular, dome-like structure that is made from willow branches and covered by hides or blankets, with a circular rock pit in the middle. Traditional Indigenous sweat lodge ceremonies typically begin with a spiritual purification (smudging) of the lodge, using sacred herbal

*The term "Indigenous" is used internationally and was adopted by the United Nations (UN). Within the UN "Indigenous" refers "broadly to peoples of long settlement and connection to specific lands who have been adversely affected by incursions by industrial economies, displacements, and settlement of their traditional territories by others." ${ }^{\prime 36}$

'A highly respected individual who is held in high regard as a spiritual practitioner, leader, role model, and mentor and plays a prominent role in his or her community and is recognized as having knowledge of Indigenous history, languages, customs, traditions. ${ }^{37}$

In this context Elder Emil Durocher's identity is public knowledge. In addition, he provided oral consent to have his name associated with his responses. medicines such as sage. Rocks are heated in a fire pit, and then placed in a rock pit at the center of the lodge. The ceremony is conducted in total darkness and consists of four rounds, during which water is poured on the rocks, creating steam, and participants are invited to pray to Creator.

In the Canadian context, the goal of historical policies governing Indigenous communities was to "cause Aboriginal $^{\S}$ peoples to cease to exist as distinct legal, social, cultural, religious, and racial entities in Canada.",2 As explained by Canada's TRC, a central element of these policies was the church-run residential schooling system. Residential schools were established throughout Canada to eliminate Indigenous culture and identity by separating Indigenous children from their families. Indigenous children who attended these schools were forced to withstand subpar conditions and often times physical, mental, and sexual abuse.

In response to the profound impacts of residential schools on Indigenous people, and to advance reconciliation in Canada, the TRC has presented 94 Calls to Action, ${ }^{2}$ one of which states:

We call upon those who can effect change within the $\mathrm{Ca}$ nadian health-care system to recognize the value of Aboriginal healing practices and use them in the treatment of Aboriginal patients in collaboration with Aboriginal healers** and Elders where requested by Aboriginal patients.

This call is closely aligned with the UN Declaration on the Rights of Indigenous Peoples, ${ }^{8}$ which in response to the injustices faced worldwide by Indigenous people asserts:

(1) Indigenous peoples have the right to their traditional medicines and to maintain their health practices ... Indigenous individuals also have the right to access, without any discrimination, to all social and health services.

(2) Indigenous individuals have an equal right to the enjoyment of the highest attainable standard of physical and mental health. States shall take the necessary steps with a view to achieving progressively the full realization of this right.

The purpose of this inquiry was not to examine the efficacy of the traditional Indigenous sweat lodge, a sacred ceremony with deep cultural roots that has withstood the test of time. Rather, aligned with TRC and UN imperatives, this work aims to investigate strategies for implementing an expansion of the traditional Indigenous sweat lodge ceremony within AHS, to better provide Indigenous peoples living in Alberta with a vital opportunity to address their holistic health needs. Before presenting the study's methods, it is important to address this work's theoretical parameters.

§The term "Aboriginal" was adopted by the Canadian Government in 1982 when the Canadian Constitution referred to the term as the "first inhabitants of Canada and includes First Nations, Inuit, and Métis." ${ }^{\text {36 }}$ However, it should be noted that more recently the Canadian Government has committed to adopting the term "Indigenous."

**An individual who may or may not be an Elder and is recognized as having knowledge of traditional medicines and healing. ${ }^{37} \mathrm{He}$ or she performs healing ceremonies with individuals and communities. 
Table 1. Interviews and Focus Group Questions

\begin{tabular}{|c|c|c|}
\hline Method & Participants & $\begin{array}{c}\text { Elder, Cultural Helper, and AHS administrative employee } \\
\text { interview and focus group questions }\end{array}$ \\
\hline Interview & $\begin{array}{l}\text { Two Elders and one } \\
\text { Cultural Helper }\end{array}$ & $\begin{array}{l}\text { (1) Describe what options are available for Indigenous community members to } \\
\text { participate in traditional Indigenous sweat lodge ceremonies? } \\
\text { (2) Describe the barriers that exist regarding including a traditional Indigenous sweat } \\
\text { lodge ceremony as part of AHS? } \\
\text { (3) What needs to be done to address these barriers? } \\
\text { (4) What would the benefits be to Indigenous community members who access AHS } \\
\text { if traditional Indigenous sweat lodge ceremonies were offered as part of the } \\
\text { service? } \\
\text { (5) Describe the culturally appropriate protocols and processes AHS must consider } \\
\text { when establishing a traditional Indigenous sweat lodge? }\end{array}$ \\
\hline Focus group & $\begin{array}{l}\text { Five AHS } \\
\text { administrative } \\
\text { employees }\end{array}$ & $\begin{array}{l}\text { (1) What can AHS do to support traditional Indigenous natural laws and protocols? } \\
\text { (2) How can AHS increase knowledge and awareness of the Indigenous cultural } \\
\text { context in Alberta? }\end{array}$ \\
\hline $\begin{array}{l}\text { Follow-up } \\
\text { interview }\end{array}$ & $\begin{array}{l}\text { Two AHS } \\
\text { administrative } \\
\text { employees }\end{array}$ & $\begin{array}{l}\text { (3) How can AHS empower individuals to participate in traditional Indigenous sweat } \\
\text { lodge ceremonies within AHS? } \\
\text { (4) How can AHS increase awareness and processes to support individuals to } \\
\text { participate in traditional Indigenous sweat lodge ceremonies within AHS? } \\
\text { (5) What additional resources are available to support the scale-up and spread of the } \\
\text { traditional Indigenous sweat lodge ceremony within AHS? }\end{array}$ \\
\hline
\end{tabular}

AHS, Alberta Health Services.

\section{Theory}

Two primary theoretical concepts underpin this work as a whole: ethical space and cultural safety.

Ethical space is a theoretical principle that recognizes and seeks to redress the historical and ongoing wrongs committed against Indigenous peoples with the context of European colonialism. Ermine, a Cree Ethicist, observed that dominant cultural frameworks in "Western" societies are implicitly predicated on Eurocentric concepts of cultural singularity, in which Indigenous knowledges and practices are fundamentally subordinated. Indigenous peoples, he writes, encounter a "brick wall of a deeply embedded belief and practice of Western universality ... a singular world consciousness, a monoculture with a claim to one model of humanity and one model of society." 9 In an "ethical space of engagement," by contrast, he proposes that principles of mutual cultural equality replace frameworks of universal cultural dominance, permitting a more neutral zone for discourse and transformative action to take place, including in institutions such as health care systems.

Aligned with the principle of ethical space, cultural safety is a concept that was originally developed by Maori Indigenous nurses working in New Zealand health care settings. ${ }^{10-12}$ The related concept of "cultural competency", prioritizes culturally sensitive care, and focuses on health care leaders and employers identifying and transforming their individual biases and assumptions. ${ }^{13}$ Cultural safety goes yet further to emphasize "respectful engagement that recognizes and strives to address power imbalances" in health care contexts. ${ }^{14}$

\section{Methods}

This study was conducted within an action research framework, aimed at developing solutions to problems experienced by stakeholders in a specific organizational context with reference to democratic, equitable, liberating, and life-enhancing principles. ${ }^{15}$ More specifically, this inquiry employed the action learning modality, in which members of a particular organization collaborate to learn about their organizational actions. ${ }^{16}$ Data generation within this framework took place via in-depth interviews and a focus group, with reference to an informed consent process approved by Royal Roads University and the University of Alberta's ethics review board. This research also adheres explicitly to respectful and rigorous Indigenous research methodological principles.

\section{Interviews and focus group}

The researcher conducted six interviews and one focus group, each about $1 \mathrm{~h}$ in length, audio-recorded and transcribed for subsequent analysis. All participants were provided with an opportunity to review their transcript for accuracy. ${ }^{17}$ Table 1 presents an overview of the interviews and focus group conducted, along with the questions posed of participants. The interviews and focus group, undertaken in two cycles, were structured to confront real issues in a critically subjective manner ${ }^{16}$ aimed at permitting triangulation across data types. ${ }^{18}$

The first data collection cycle involved semistructured, in-depth interviews with two Elders, one Cultural Helper, ${ }^{\dagger \dagger}$ and three Indigenous community members. The interview guides were developed in consultation with and Organizational Sponsor from within AHS and an Inquiry Team. The Elders and Cultural Helper were recruited because they were associated with the Indigenous Health Program within AHS and possessed knowledge regarding the cultural protocols surrounding the traditional Indigenous sweat lodge

\footnotetext{
${ }^{\dagger \dagger}$ Within the context of AHS, an individual who is recognized as having knowledge of Indigenous history, languages, customs, and traditions and works with Elders to support Indigenous clients.

Two Elders and three AHS employees.
} 
ceremony. The Organizational Sponsor created space and opportunities for the researcher to develop personal relationships with the Elders and Cultural Helper. The Indigenous community members were recruited on the basis of their previous usage of AHS services and participation in the traditional Indigenous sweat lodge ceremony.

In the second data collection cycle, the author conducted a focus group with seven AHS administrative employees. Additional interviews were conducted with two AHS administrative employees who were not able to attend the focus group. The AHS administrative employees were recruited for participation because of their decision-making role related to the subject of this inquiry. The discussion guide for the second phase of data collection was informed by the key themes that emerged from the first cycle of interviews.

\section{Indigenous research principles}

All portions of this study were conducted with reference to accepted tenets of Indigenous research methodology that acknowledge oral traditions and community knowledge, namely the principles of supporting ownership, control, access, and possession. ${ }^{19}$ To this end, the researcher respectfully offered tobacco to the Elders and Cultural Helper to honor their participation, and provided them the option to provide written or oral consent, to have their names associated with their responses or to remain anonymous, and gave them an oral recording of their interview. The Elders and Cultural Helper furthermore "member checked" the completed documented inquiry, to ensure it was presented within the appropriate context. ${ }^{20}$

\section{Analysis}

Interview and focus group transcripts were analyzed with reference to the identified theoretical parameters using a constant comparative methodology informed by grounded theory. ${ }^{21}$ In this approach, open coding was used first to compare responses to identify categories, properties, and dimensions. ${ }^{22}$ Axial coding was then used to move responses together in new ways. Finally, selective coding was used to systematically select high-level and supporting categories.

The results of this analysis are presented in what follows. Readers will note that the interviewed Elders and Cultural Helper chose to have their names associated with their responses, whereas all other participant excerpts are coded to ensure anonymity. Indigenous community members' responses are identified using codes ICM 1-3; AHS administrative employee responses are coded as AE 1-7.

\section{Results}

Throughout the interviews and focus group conducted, participants consistently emphasized the importance of increasing efforts to expand traditional Indigenous healing practices within AHS. The primary theme evident across the data may thus be characterized as follows:

Expanding traditional Indigenous healing practices within AHS. Five additional supporting subthemes emerged, as follows:

(1) enhancing cultural competency and safety training among leadership and employees;
(2) Adhering to tradition and protocol;

(3) Establishing meaningful partnerships;

(4) Strengthening organizational facets of program delivery; and

(5) Need for additional financial, human, and logistical resources.

Each of the study themes is elaborated in what follows, supported by verbatim excerpts from study field data.

\section{Expanding traditional Indigenous healing practices within AHS}

Both Indigenous participants and AHS administrators articulated a readiness to expand the traditional Indigenous sweat lodge ceremony within AHS. Elder Clifford Cardinal noted, "In terms of time to talk about this, I think now is the time." A senior leader asserted: "It's certainly the climate, as an organization ... We're at a state of readiness which I think more so then I feel perhaps then we've ever been" (AE-1). Cultural Helper Janice Shirt echoed the need to expand the traditional Indigenous sweat lodge within AHS, arguing, "There is a greater need than just one, one sweat lodge ... the need is great and the opportunity is limited ... there is a huge gap."

That said, some participants cautioned against taking a reductionist approach that exclusively focused on the traditional Indigenous sweat lodge ceremony. Instead, they advocated for a broader approach to traditional Indigenous healing practices. Elder Emil Durocher questions:

How much do you want to know? Or are you just wanting this and this and this. If you do that, then you'll be taking parts of a puzzle and trying to make a whole, when actually it takes all of them to make a whole.

A manager (AE-2) equally asserted:

I think when we look at this, we gotta look at it in a way that it probably much larger than just a sweat lodge ceremony but there is other opportunities where we can tap into some of those ceremonies that are going to help with that healing and that wellness of the individuals ... There is many sacred ceremonies that create that healing.

\section{$\mathrm{He}(\mathrm{AE}-2)$ further notes:}

[W]ithin Alberta Health Services we do have sacred spaces within the facilities. In Lethbridge at the Chinook Regional Hospital we have a ceremonial room that we utilize for various ceremonies, whether it's a pipe ceremony, smudge ceremonies, face painting, ahh different types of ceremonies that recognize from the local Blackfoot culture. Within Calgary at the Elbow River Healing Lodge we have a ceremonial room also that we utilize, very similar. So really when we are looking at sacred spaces we [AHS] already have some but we just need to expand on those to bring them outdoors so that we can accommodate possibly a sweat lodge ceremony.

\section{Enhancing cultural competency and safety training among leadership and employees}

Participants strongly articulated a need to enhance cultural competency and safety training among AHS leadership and employees. Describing the current state of related trainings in this regard within AHS, a manager (AE-2) acknowledged: 
There are some good products developed within AHS within the Indigenous Health Program. We have e-training, which is seven modules ... we have orientation ... but I don't think we're to the point where we're utilizing these tools to gain that knowledge and understanding ... The e-training is only a first step, the second step is we do hold cultural awareness and sensitivity in person sessions ... but I think the first step is, is for the organization to recognize and support this type of training, so for all employees.

Others, such as one senior leader (AE-3), spoke more directly to the type of content that such training should increasingly address:

It is absolutely true that I think it needs to start with a real communal understanding of, of the ceremony, of the history, of the traditions ... It almost has to be like it's a level of awareness that needs to be planned and it needs to be strategic in, I think it needs to be an organizational priority.

Elder Emil Durocher emphasized that to advance cultural competency and safety among AHS leaders and employees, training should be experiential rather than formalized: "The best thing a person can do is try to learn these traditions and the protocols because I can't write them and I can't share them."

Addressing the personal responsibility of individual AHS leaders to become better sensitized to the delivery of culturally competent and safe care, as well as specific traditional healing protocols, another senior leader asserted: "We as leaders have a responsibility, and need to enhance our own personal awareness and need to work through things. So, I think we're starting to get there but we clearly have a long ways to go" (AE-4). She further extended her stance to include frontline employees within AHS, noting: "We need to ensure that there is a cultural competency process in place so that the sites are fully aware or knowledgeable on the protocols and also the local Indigenous culture" (AE-4).

\section{Adhering to tradition and protocol}

Several participants focused on adherence to traditional knowledge and Indigenous protocols as a key component of successful integration of the sweat lodge into the AHS. Elder Emil Durocher in particular emphasized: "Traditional, is keeping the laws, natural laws in place. That you don't break it." He further elaborated: "The sweat lodge itself that I do is closest to the Indigenous traditional sweat lodge. What that means is, I was a given the right to hold a sweat, or to keep, be the keeper of a sweat lodge."

AHS staff largely concurred, also drawing attention to the diversity of Indigenous traditions across the region being served. One manager for instance noted: "We have to keep in mind that there are many protocols. Within Alberta alone there are many tribes, whether they are from the South to the North, and they have different ways of doing things and different requirements" (AE-2). A Medical Officer of Health (AE-5) advised that AHS staff work to understand:

$[\mathrm{L}]$ ocal variations in the ceremony, and working with local Elders to have a better understanding of how to make it appropriate for that area of the province ... find out what their wants are and what their needs are, and where does the Indigenous ceremony fit compared to smudging or as compared to other types of ceremonies that are performed. Which ones are more important for them and how do we best serve them in the facilities that are close to that community.

\section{Establishing meaningful partnerships}

Several participants emphasized a need to develop meaningful partnerships between Indigenous community leaders and institutional stakeholders. As one manager (AE2) explained, such partnerships are vital to support the sustainability of programs:

Be able to work together in, in identifying an supporting this need of having this sacred space and having these types of ceremonies; because if you do it on your own then they, they don't tend to last as long as were hoping ... we really need to have that partnership within AHS to really fully understand the significance of how this helps with the healing and the health of, of the participants that are a part of this sacred ceremony.

A Medical Officer of Health (AE-5) furthermore underscored the role of partnerships in leveraging (rather than duplicating) existing resources:

Utilization of other resources and communities, so if there's a community that already has a sweat lodge, can AHS develop an understanding with them to share that resource cause I don't think we should redevelop everything, we should use what we have.

Building partnerships, as Cultural Helper Janice Shirt emphasized, should rely on respectful and open relations between local Indigenous and institutional leaders. Not only did she recommend that AHS leaders and employees approach Elders within AHS, but also that they approach local community Elders to support the development of community partnerships and to ensure adherence to unique local traditions and protocols: "Definitely approach Emil and give him tobacco, and have a discussion with him to let him know our plans... it's not, you know, only him, it's also the community Elders of this area."

\section{Strengthening organizational facets of program delivery}

Indigenous and institutional participants alike repeatedly alluded to the importance of strengthening organizational facets of program delivery, drawing attention to existing challenges in this regard. As one senior leader (AE-4) noted, additional work would be needed to address some biomedical physicians' lack of openness to nonbiomedical modes of healing:

We need to have some focused discussions with some of our physician leadership. There's a real reluctance to look at or to even consider amongst many of them to look at having some complementary approaches to healing and treatment and so I think that just even some targeted discussions so we start evolving that conversation.

The success of Indigenous Health Programs within AHS, she argued, will depend on greater buy-in and awareness of existing programs by organizational leadership and frontline staff alike: "I think it's important that our Indigenous Health Program be aligned ... if this is something we are going to pursue, we need everyone aligned" (AE-4). A Medical Officer of Health echoed this stance, noting: "I have been working with the Indigenous Health Program for about eight months now and I did not realize this [traditional Indigenous sweat lodge at AHE] existed. So I think we can educate our staff about it" (AE-5). 
Community participants affirmed the importance of enhanced program awareness in improving program delivery. One participant for instance noted, "For a long time I was kinda looking for a lot of stuff but it was always in the wrong places" (ICM-1). Another participant similarly reported: "I was never told that there was actually sweats going on there $[\mathrm{AHE}]$... During my stay there I never did get to go to the ceremonies ... Nobody ever took me to the ceremonial grounds" (ICM-2).

\section{Need for additional financial, human, and logistical resources}

Several participants advocated strongly that additional fiscal, human, and logistical resources be made available to optimize success of the traditional Indigenous sweat lodge implementation in AHS.

Financially speaking, Cultural Helper Janice Shirt notes, "There is only so much funding ... to buy the wood and to pay for the gas to go and collect the rocks and, and to give protocol to the Elder for, for a sweat." A community participant drew attention to the impacts of insufficient financial support for a sacred ceremony: "I see a lot of women show up and they don't have skirts ... and even the men, not having shorts ... and the men and the women not having towels" (ICM-2). A manager explains, "After a sweat lodge there is always a feast and that's a part of that ceremony, so you know the cost of that feast", (AE-2).

From a human resources perspective, Cultural Helper Janice Shirt commented on the lack of support for clients to attend traditional Indigenous sweat lodge ceremonies:

I am the only Indigenous Cultural Helper at Alberta Hospital [AHE] and so the patients are consistently asking me, can you ... escort us there, escort us back and attend with us and I would love to but I am also required to be at the other hospitals so I am only there two days a week.

In relation to logistics, she further noted: "I do get requests for ceremony, for a sweat lodge ceremony and there's no transportation for people to attend a sweat lodge."

\section{Discussion and Conclusions}

Within an action research framework, this article presents the results of a study aimed at investigating strategies for expanding the creation of space for a particular traditional Indigenous healing ceremony, the traditional Indigenous sweat lodge, in a Canadian public health care setting focused on mental health. In line with the theoretical principles of ethical space and cultural safety, and echoing the priorities identified by the UN and TRC, this work positions the voices of Elders, a Cultural Helper, and Indigenous community members as central, alongside the perspectives of public health care leaders and employees.

On the whole, all participants concurred that the time was ripe for further expansion of the traditional Indigenous sweat lodge ceremony within AHS. Analyzed data from qualitative interviews and focus groups provide important details about the types of action and perspectives needed to advance the project moving forward. Findings furthermore point to key principles in creating space for traditional Indigenous healing practices in health care settings beyond AHS, in Canada, and other jurisdictions impacted by European colonialism.
Participants recognized that AHS had previously made some degree of progress in including sacred spaces for traditional Indigenous healing practices within its facilities. Indeed, in addition to the traditional Indigenous sweat lodge ceremonies held at AHE by Elder Emil Durocher, a number of other AHS facilities have sacred spaces for traditional Indigenous healing ceremonies. Some formalized, Indigenous health care training programs have also been implemented for AHS leaders and employees; and relationships have been fostered between AHS leaders and some Elders and Indigenous community members. However, participants emphasized that much work remains to be done. As detailed hereunder, findings make clear that future action should be undertaken in such a way as to centralize the principles of ethical space and cultural safety in relation to the values, traditions, and practices of Indigenous peoples.

With regard to cultural competency and safety training for AHS leaders and employees, Elder Emil Durocher spoke of the importance of experiential rather than exclusively didactic employee trainings, including leader and employee participation in (rather than simply hearing about) traditional Indigenous cultural events and healing practices. Such a training approach would inevitably challenge health care workers to confront their own biases and assumptions, including some professionals' lack of openness to nonbiomedical therapeutic approaches. Ultimately, considering cultural safety training from an ethical space standpoint, such programs would also do well to address Canada's history of colonization and the country's commitment to state multiculturalism as now discussed.

As Bannerji notes, "Colonialism is the context or entry point that allows us to begin exploring the social relations and cultural forms that characterize these relations." 23 It is vital that health care leaders and employees thoroughly understand the context in which colonization took place, and Indigenous people's collective sui generis rights, which are inherent due to their unique relationship with the Government of Canada. ${ }^{24}$ In addition, health care leaders and employees need to understand the commitments that were made through various multicultural policies, including the Royal Commission on Bilingualism and Biculturalism, ${ }^{25}$ the Canadian Charter of Rights and Freedoms, ${ }^{26}$ and the Multiculturalism Policy of Canada. ${ }^{27}$

Significantly, increased cultural awareness among health care leaders and employees might also help promote creation and recognition of policies and procedures that support Indigenous ways of knowing and being, as well as nonsupportive policies and procedures. This in turn would permit health care leaders and employees to develop more meaningful community relationships and ensure the successful provisions of culturally appropriate traditional Indigenous healing practices.

The importance of preserving the integrity of traditional Indigenous healing practices by adhering to tradition and protocol might furthermore be communicated in employee trainings. This point is also essential in considering the structural dimensions of ethical spaces in which Indigenous ceremonies may be included in biomedically dominant, provincial health systems contexts. Indeed, it is not enough to integrate traditional Indigenous healing practices within Canadian health care systems that may simply produce an extension of colonial assimilation policies. ${ }^{28}$ The establishment 
of culturally appropriate, meaningful partnerships is a key precondition for creation of "ethical space[s] of engagement." In such settings, health care leaders and employees may consult with Elders, Knowledge Keepers, ${ }^{\S \S}$ and Healers creating a neutral zone of human-to-human discourse in which multiple worldviews may coexist and have their inherent value respected.

Such partnerships would permit three key issues-each aligned with UN and TRC imperatives to be better addressed in health system contexts. First, teams of stakeholders may effectively assess community priorities and system readiness for traditional Indigenous healing practices programs to be implemented. Second, in contexts where readiness has been established, Elders, Knowledge Keepers, and Healers may define and assert Indigenous rights to traditional medicines and healing practices within the health care system. Third, such partnerships would support ongoing consultation aimed at protection and preservation of the integrity of traditional Indigenous healing practices from exploitation and misappropriation.

Findings also point to more tangible organizational and logistic considerations in expanding traditional Indigenous healing practices in a provincial health care setting. Multiple participants identified a need for greater intraorganizational efforts to coordinate information being appropriately shared with leaders, employees, clients, and community members alike about traditional Indigenous sweat lodges and other traditional Indigenous healing practices taking place within their facilities. Given that health care registration systems do not always allow for the identification of Indigenous clients, there would be value in a future inquiry focused on appropriate ethnocultural self-identification processes aimed at enhancing culturally appropriate care. Participants in this inquiry also made clear that sufficient financial and human resources need to be made available if the inclusion of Indigenous healing practices within provincial health systems settings is to be successful: a point that must be addressed by leadership from the outset.

It is clear that there are various organizational requirements needed to successfully create space for traditional Indigenous healing practices within health care systems. These include the following: leadership, coordination and alignment, partnerships, awareness, delivery, and resources. A comprehensive traditional Indigenous healing practices strategic plan that informs organizational leadership, internal and external coordination and alignment, community partnership development, program awareness and delivery, and resources allocation is needed within health care systems.

In the broader Canadian context, several organizations and programs outside of AHS have successfully created space for traditional Indigenous healing practices. These include The First Nations Health Program in the Yukon, ${ }^{3}$ the Noojmowin Teg Health Centre, ${ }^{29}$ the All Nations' Healing Hospital in Fort Qu'Appelle, ${ }^{30}$ the Métis Addictions Council of Saskatchewan, Inc., ${ }^{31}$ and the Inuulitsivik midwifery service and

\footnotetext{
${ }^{\S}$ An individual who has been transferred sacred rights to uphold, maintain, and sustain oral culture and traditions through generations. ${ }^{37}$ In acceptance of these rights he or she makes a life-long commitment to carrying out this "way of life" and to supporting his or her community.
}

education program. ${ }^{32}$ All these organizations and programs employ unique governance and funding structures. A closer review of these organizations and programs would help to evaluate successes and challenges with regard to appropriate governance structures, culturally appropriate processes to support partnership development, program awareness and delivery, and resource allocation.

Strategically, such a review would complement future study on the development of more experiential and inclusive cultural competency leadership and employee training efforts, as well as research aimed at learning from organizations and programs that have successfully created space for traditional Indigenous healing practices. Such future study aimed at defining culturally safe parameters for Indigenous peoples' health care and premised on the theoretical principle of ethical space would serve to further addresses the articulated priorities of the UN and TRC on this subject. Implementation of such studies' recommendations - as with those proposed in this study may furthermore help to prevent further stresses in social relations between Indigenous and non-Indigenous people in postcolonial contexts.

This study's results are firmly grounded in study methods that honor Indigenous ways of knowing, and are supported by direct quotes from participants based on their lived experiences. That being said, it is important to recognize that the researcher is a non-Indigenous person, which is a clear limitation of this work given that the inquiry is presented from the researcher's personal analytic vantage point. Despite having consciously worked to eliminate cultural bias by embracing traditional Indigenous ways of knowing and being, and by adhering to culturally appropriate protocols, complete cultural relativism can never be fully achieved. ${ }^{33}$ Despite efforts to be inclusive within, it warrants further note that this inquiry did not seek to reflect the perspectives of all Indigenous peoples living in Alberta.

Healing among Indigenous people living in Canada continues to represent a complex system of practices and interrelating priorities. ${ }^{29}$ As Elder Emil Durocher points out, the traditional Indigenous sweat lodge ceremony is just one of many ceremonies that contributes to this system. ${ }^{34}$ It is thus important that efforts to create space for traditional Indigenous healing practices within biomedically dominant health care structures not be undertaken in a reductionist manner.

Instead, a broad approach is needed, which (1) recognizes diverse ways of knowing and being (rather than reproducing a "singular world consciousness") ${ }^{9}$; (2) respects geographic and cultural diversity within Indigenous knowledge ${ }^{35}$; (3) understands that each Indigenous community and individual is unique; and (4) adheres holistically to traditional Indigenous healing protocols.

During this time of reconciliation with Indigenous peoples in Canada and beyond, health care leaders and providers have an ethical responsibility and important opportunity to help improve the troubling health disparities at hand. This will inevitably require tremendous reflection, humility, courage, and commitment by stakeholders at all levels, as they work to transform health systems that disproportionately disadvantage Indigenous ways of knowing and being while implicitly privileging Eurocentric, biomedical perspectives. This pursuit, despite the barriers that may arise, is a moral, social, and political imperative for all those health care workers who seek to reduce suffering. As 
Elder Clifford Cardinal concluded, "health being what it is, the budget being what it is, we better make peace."

\section{Acknowledgments}

The author sincerely thanks the Organizational Sponsor, Marty Landrie, Academic Supervisor, Magdalena Smolewski, and Second Committee Reviewer, Elizabeth Hartney for the commitment to personal learning and development. The author also thanks Elder Casey Eagle Speaker and Elder Mike Lickers for sitting on the Inquiry Team and sharing their wisdom and guiding the inquiry process. The author thanks Carol Brzezicki, Randal Bell, and Scott Calling Last for also sitting on the Inquiry Team and sharing their knowledge and expertise. The author also thanks Elder Emil Durocher, Elder Clifford Cardinal, Cultural Helper Janice Shirt, as well as all the Indigenous community members, and AHS administrative employees for graciously sharing their thoughts, perspectives, and professional opinions. Finally, the author thanks Nadine Ijaz for supporting to ensure this publication became a reality.

\section{Author Disclosure Statement}

No competing financial interests exist.

\section{References}

1. Government of Alberta. First nations-Health trends Alberta. 2016. Online document at: www.afnigc.ca/main/ includes/media/pdf/fnhta/HTAFN-2016-05-31-LifeExp2.pdf, accessed December 24, 2018.

2. Truth and Reconciliation Commission of Canada. Honouring the truth, reconciling for the future: Summary of the final report of the Truth and Reconciliation Commission of Canada. 2015. Online document at: www.nctr.ca/assets/ reports/Final\%20Reports/Executive_Summary_English_Web .pdf, accessed December 24, 2018.

3. National Aboriginal Health Organization. An overview of traditional knowledge and medicine and public health in Canada. 2008. Online document at: www.tools.hhr-rhs.ca/ index.php?option=com_mtree\&task=att_download\&link_id= 7878\&cf_id=68\&lang=en, accessed December 24, 2018.

4. Royal Commission on Aboriginal Peoples. Report of the royal commission on Aboriginal peoples vol 3: Gathering strength. 1996. Online document at: http://data2.archives.ca/ e/e448/e011188230-03.pdf, accessed October 23, 2018.

5. Alberta Health Services. About AHS. Online document at: www.albertahealthservices.ca/about/about.aspx, accessed December 24, 2018.

6. Alberta Health Services. Hospitals \& facilities: Alberta Hospital Edmonton. Online document at: www.alberta healthservices.ca/findhealth/facility.aspx?id=6337, accessed December 24, 2018.

7. Schiff JW, Pelech W. The sweat lodge ceremony for spiritual healing. J Relig Spiritual Soc Work 2007;26:71-93.

8. United Nations. The United Nations declaration on the rights of Indigenous peoples. 2008. Online document at: www.un.org/esa/socdev/unpfii/documents/DRIPS_en.pdf, accessed December 24, 2018.

9. Ermine W. The ethical space of engagement. Indigenous LJ 2007;6:193-203.

10. Anderson J, Perry J, Blue C, et al. "Rewriting” cultural safety within the postcolonial and postnational feminist project: Towards new epistemologies of healing. ANS Adv Nurs Sci 2003;3:196-214.

11. Ramsden I. Kawa whakaruruhau: Cultural safety in nursing education in Aotearoa. Nurs Prax N Z 1993;8:4-10.

12. Ramsden I. Cultural safety/kawa whakaruruhau ten years on: A personal overview. Nurs Prax N Z 2000;15:4-12.

13. Clifford A, Mccalman J, Bainbridge R, Tsey K. Interventions to improve cultural competency in health care for Indigenous people of Australia, New Zealand, Canada and the USA: A systematic review, Int J Qual Health Care 2015: 27:89-98.

14. First Nations Health Authority. \#itstartswithme: FNHA's policy statement on cultural safety and humility. Online document at: www.fnha.ca/documents/fnha-policy-statementcultural-safety-and-humility.pdf, accessed December 24, 2018.

15. Stringer ET. Action Research (4th ed.). Thousand Oaks, CA: Sage, 2014.

16. Coghlan D, Brannick T. Doing Action Research in Your Own Organization (4th ed.). Thousand Oaks, CA: Sage, 2014.

17. Birt L, Scott S, Cavers D, et al. Member checking: A tool to enhance trustworthiness or merely a nod to validation? Qual Health Res 2016;26:1802-1811.

18. Glesne C. Becoming Qualitative Researchers: An Introduction (5th ed.). Boston, MA: Pearson, 2016.

19. Alberta First Nations Information Governance Centre. Protecting our knowledge telling our stories strengthening our communities. 2013. Online document at: www. afnigc.ca/main/index.php?id=home, accessed December 24, 2018.

20. Koelsch LE. Reconceptualizing the member check interview. Int J Qual Methods 2013;12:168-179.

21. Glaser BG, Strauss AL. The Discovery of Grounded Theory: Strategies for Qualitative Research. Hawthorn, NJ: Aldine Transaction, 1967.

22. Corbin J, Strauss A. Basics of Qualitative Research: Techniques and Procedures for Developing Grounded Theory (3rd ed.). Thousand Oaks, CA: Sage Publications, Inc., 2008.

23. Bannerji $\mathrm{H}$. On the dark side of the nation: Politics of multiculturalism and the state of Canada. J Can Stud 2000; 31:103-128.

24. MacDonald DB. Aboriginal peoples and multicultural reform in Canada: Prospects for a new binational society. Can J Sociol 2014;39:65-86.

25. Dewing M. Canadian multiculturalism. 2013. Online document at: www.multiculturalmentalhealth.ca/wp-content/ uploads/2014/01/Dewing_Multiculturalism_2009-20-e.pdf, accessed December 24, 2018.

26. Justice Laws Website. Constitution Act, 1982: Part 1Canadian charter of rights and freedoms. 2018. Online document at: www.laws-lois.justice.gc.ca/eng/Const/page15.html, accessed December 24, 2018.

27. Justice Laws Website. Canadian Multiculturalism Act. (R.S.C., 1985, c. 24, [4th Supp.]). 2018. Online document at: https://laws-lois.justice.gc.ca/PDF/C-18.7.pdf, accessed December 24, 2018.

28. Rudmin FW. Critical history of the acculturation psychology of assimilation, separation, integration, and marginalization. Rev Gen Psychol 2003;7:3-37.

29. Maar M. Clearing the path for community health empowerment: Integrating health care services at an Aboriginal health access centre in rural central Ontario. J Aborig Health 2004;1:54-64. 
30. File Hills Qu'Appelle Tribal Council. The All Nations Healing Hospital and File Hills Qu'Appelle Tribal Council Health Services. 2018. Online document at: www.afn.ca/ wp-content/uploads/2018/03/All-Nations-Healing-Hospital .pdf, accessed December 24, 2018.

31. Métis Addictions Council of Saskatchewan, Inc. Annual report: A year in review 2014-2015. 2015. Online document at: www.macsi.ca/wp-content/uploads/2018/03/ Annual_Report_2014-2015F.pdf, accessed December 24, 2018.

32. Van Wagner V, Epoo B, Nastapoka J, Harney E. Reclaiming birth, health and community: Midwifery in the Inuit villages of Nunavik, Canada. J Midwifery Womens Health 2007;52;384-391.

33. Sarniak R. 9 Types of research bias and how to avoid them. 2015. Online document at: www.quirks.com/articles/9types-of-research-bias-and-how-to-avoid-them, accessed December 24, 2018.

34. Poonwassie A, Charter A. Aboriginal worldview of healing. In: Moodley R, West W, eds. Integrating Traditional Healing Practices into Counseling and Psychotherapy. Thousand Oaks, CA: Sage, 2005:15-24.
35. Martin Hill D. Traditional medicine in contemporary contexts: Protecting and respecting Indigenous knowledge and medicine. 2003. Online document at: http://epub.sub.unihamburg.de/epub/volltexte/2013/15417/pdf/research_tradition .pdf, accessed December 24, 2018.

36. First Nations Studies Program. Indigenousfoundations.arts .ubc.ca. 2009. Online document at: https://indigenousfoundations .arts.ubc.ca/terminology, accessed December 24, 2018.

37. Alberta Health Services. Alberta Health Services guide for Indigenous traditional protocols (internal document). 2018. Online document at: https://www.hinton.ca/DocumentCenter/ View/6825/AHS-Guidelines-for-Indigenous-TraditionalProtocols, accessed January 24, 2019.

Address correspondence to: Jazmine Leigh Drost, MPH, MA Royal Roads University 202-701 56 Avenue SW Calgary Canada T2V OG9

E-mail: Jazmine.Drost@ahs.ca 